SHORT REPORT

\title{
Role of intravenous urogram in investigation of urinary tract infection: an observational study
}

\author{
B Padmakumar, H M Carty, D A Hughes, B A Judd
}

Postgrad Med J 2004;80:424-425. doi: 10.1136/pgmi.2003.011148

See end of article for authors' affiliations

.....................

Correspondence to:

Dr B Padmakumar, Royal Oldham Hospital,

Rochdale Road, Oldham OL12JH, UK; Beena.

Padmakumar@pat.nhs.uk

Submitted 12 June 2003 Accepted 30 July 2003

\begin{abstract}
Objectives: To examine the value of an intravenous urogram (IVU) in patients with abnormal differential

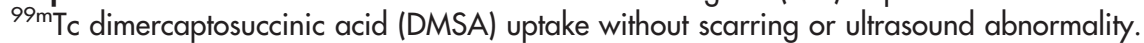

Study design: Forty patients (age 0-19 years) were identified over a two year period in whom the differential renal uptake was $>10 \%$, who had smooth renal outlines, and had no evidence of scarring. All patients had an ultrasound examination. Two had marked urological abnormalities on ultrasound and eight had a duplex system in the kidney with greater DMSA uptake. In 18 patients where no explanation was apparent for the discrepant DMSA uptake, an IVU was performed.

Results: Eight patients had a normal IVU. In the remaining 10 patients, six had duplex systems without scarring and four had appearances of scarring in the kidney with reduced DMSA uptake.

Conclusions: In this small selected group an IVU will identify a significant number of patients with normal kidneys, unrecognised simple duplex systems, or scarring where the DMSA scan has been inconclusive. This will help in planning long term follow up.
\end{abstract}

U rinary tract infection remains a common paediatric problem with a risk of developing renal scarring and associated hypertension. Renal scintigraphy using a ${ }^{99 \mathrm{~m}}$ Tc dimercaptosuccinic acid (DMSA) scan has been shown to be more sensitive than an intravenous urogram (IVU) in detecting renal scars. ${ }^{1-5}$ The IVU provides good anatomical information of the urinary tract and is a useful supplement to ultrasound and DMSA scans. ${ }^{6}$ Although many DMSA scans will show clear evidence of scarring, others may show a differential renal uptake outside the accepted normal range of $10 \%$ but have smooth outlines. Some of these may be associated with duplex systems or undetected scarring. In those patients where a clear cause could not be identified for the discrepant renal function, IVUs have been performed to define the renal anatomy. We report our findings on the diagnostic role of the IVU in this selected group of patients.

\section{PATIENTS AND METHODS}

A total of 520 patients (age 0-19 years) underwent DMSA scanning over a two year period after presenting to nephrology and urology clinics at the Royal Liverpool Children's Hospital Alder Hey. The doses of ${ }^{99 \mathrm{~m}}$ Tc DMSA were calculated according to the child's surface area using the adult standard of $80 \mathrm{MBq}$. Both posterior and posterior oblique images were obtained two hours after administration of the radiopharmaceutical isotope. Forty patients $(7.7 \%)$ were identified in whom differential DMSA uptake was greater than $10 \%$, with smooth renal outlines, and no evidence of renal scarring. This discrepancy is accepted as being abnormal in this hospital and is supported by the recent consensus on DMSA scans by the Scientific Committee of Radionuclides in Nephrology. ${ }^{7}$ Thirty five of the 40 patients investigated had presented with a urinary tract infection. Two had marked urological abnormalities on the ultrasound scans, one with moderate left hydronephrosis and megaureter, and one with a left duplex kidney and upper pole hydronephrosis. Eight patients had clear duplex anomalies on ultrasound on the same side as the kidney with the larger differential DMSA uptake. Six patients were lost to follow up. Three parents declined further investigations and one patient is currently awaiting further imaging. In 18 of these 40 patients who presented initially with urinary tract infections, an IVU had been undertaken as there was no apparent explanation for the abnormal DMSA uptakes. IVUs were performed using non-ionic contrast iopamidol (containing $300 \mathrm{mg}$ of iodine $/ \mathrm{ml}$ ) at a dose of $2 \mathrm{ml} / \mathrm{kg}$. An initial full length control film was followed by post-injection five minute cross kidney film and a 15 minute full length film.

\section{RESULTS}

Eighteen patients had an IVU (13 girls, five boys, age range 1-10 years, median 4 years). Four had scars (see table 1); all four were girls ages $1-7$.

Six patients had simple duplex systems without scarring. One had a bilateral duplex system, four had unilateral duplex systems with greater DMSA uptake on the side of the duplex system, and one had a bifid collecting system on the side of the lesser DMSA uptake. The DMSA divided function in these patients ranged between $37 \% / 63 \%$ and $44 \% / 56 \%$.

Eight patients had structurally normal kidneys (five boys, three girls). The divided function ranged from right 39\%/61\% to $44 \% / 56 \%$.

\section{DISCUSSION}

Many children with urinary tract infection have anatomical and functional abnormalities. DMSA has been shown to be the most sensitive method of detecting renal scars but has some shortcomings. ${ }^{8}$

The accepted normal range for differential DMSA uptake is $10 \%$. Uncomplicated simple duplex kidneys may have greater uptake in the duplex kidneys or cause an erroneous impression of a small poorly grown contralateral kidney. Duplex systems are not always recognisable on DMSA scans. A pyelonephritic kidney rarely may have peripheral scarring and appear as a small smooth kidney on DMSA scanning. Ultrasound is an excellent modality for detecting structural renal abnormalities. Uncomplicated duplex systems may be identified by observing splitting of the renal sinus echoes but this finding is not invariably present. The sensitivity of

Abbreviations: DMSA, ${ }^{99 \mathrm{~m} T c}$ dimercaptosuccinic acid; IVU, intravenous urogram 


\begin{tabular}{|c|c|c|c|}
\hline Age/sex & Ultrasound & DMSA & IVU \\
\hline $7 F$ & Normal & $\begin{array}{l}\text { Left } 57 \% \text {, right } \\
43 \%\end{array}$ & $\begin{array}{l}\text { Right kidney: } \\
\text { duplex collecting } \\
\text { system; scar in } \\
\text { right upper pole }\end{array}$ \\
\hline $8 \mathrm{~F}$ & $\begin{array}{l}\text { Right kidney: } \\
\text { simple cyst in } \\
\text { upper pole }\end{array}$ & $\begin{array}{l}\text { Left } 61 \% \text {, right } \\
39 \%\end{array}$ & $\begin{array}{l}\text { Right upper pole } \\
\text { scar }\end{array}$ \\
\hline $6 \mathrm{~F}$ & Normal & $\begin{array}{l}\text { Left } 60 \% \text {, right } \\
40 \%\end{array}$ & $\begin{array}{l}\text { Right upper pole } \\
\text { scar }\end{array}$ \\
\hline $1 F$ & Normal & $\begin{array}{l}\text { Left } 42 \% \text {, right } \\
58 \%\end{array}$ & $\begin{array}{l}\text { Bilateral duplex } \\
\text { systems, no } \\
\text { function in left } \\
\text { upper pole }\end{array}$ \\
\hline
\end{tabular}

ultrasound for detecting scarring is very variable and hence its use in the detection of scarring remains controversial. ${ }^{9}$ This study shows that an IVU may provide further structural information of the urinary tact and identifies patients with previously undetected scars (four out of 18 IVUs) and is a useful supplement to ultrasound and DMSA. Previous studies support this. ${ }^{1011}$ The extent of the divided function is no guide to discriminating between normal, scarring, or duplex systems. Scarring in our group was always on the side of poorest function. There are no studies looking at the risk of hypertension in patients with normal IVUs. However it would seem reasonable in keeping with previous practice that those patients with normal IVUs, including those who showed simple duplex kidneys on the side of greater function, could be safely discharged. Clearly those with identified scarring would need long term surveillance for hypertension.

\section{CONCLUSION}

An IVU will identify a significant number of patients with normal kidneys, unrecognised duplex systems, or scarring where DMSA has been inconclusive. This will help in planning long term follow up. We suggest that the indication for an IVU should be a discrepancy in DMSA uptake greater than $10 \%$, with no evidence of scars and where ultrasound is normal.

\section{Authors' affiliations}

B Padmakumar, D A Hughes, B A Judd, Renal Unit, Royal Liverpool

Children's Hospital, Liverpool, UK

H M Carty, Department of Radiology, Royal Liverpool Children's

Hospital, Liverpool, UK

\section{REFERENCES}

1 Rickwood AMK, Carty HM, McKendrick T, et al. Current imaging in urinary tract infections. BMJ 1992:304:663-5.

2 Verber IG, Strudley HR, Meller ST. 99-mTc-dimercaptosuccinic acids as the first investigation of urinary tract infection. Arch Dis Child 1988;63:1320-5.

3 Gleeson FV, Gordon I. Imaging in urinary tract infection. Arch Dis Child $1991 ; 66: 1282-3$.

4 Jakobson B, Soderlundh S, Berg U. Diagnostic significances of 99-mTc dimercaptosuccinic acid (DMSA) scintigraphy in urinary tract infection. Arch Dis Child 1992;67:1338-42.

5 Tappen DM, Murphy AV, Mocan H, et al. A prospective study of children with first acute symptomatic E coli urinary tract infection. Acta Paediatr Scand 1987:78:923-9.

6 Hansen A, Wagner AA, Lavard LD, et al. Diagnostic imaging in children with urinary tract infection in the role of intravenous urography. Acta Paediatrica 1995;84:84-9.

7 Piepsz A, Blaufox MD, Gordon I, et al. Consensus on renal cortical scintigraphy in children with urinary tract infection. Scientific Committee of Radionuclides in Nephrourology. Semin Nucl Med 1999;29:160-74.

8 Lavocat MP, Granion D, Guimpied Y, et al. The importance of $99 \mathrm{Tcm}-\mathrm{DMSA}$ renal scintigraphy in the follow-up of acute pyelonephritis in children: comparison with urographic data. Nucl Med Commun 1998;19:703-10.

9 Roebuck DJ, Howard RG, Metrewel C. How sensitive is ultrasound in the detection of renal scars? Br J Radiol 1999;72:345-8.

10 Hansen A, Wagner AA, Lavard LD, et al. Study of children with urinary tract infections. Does intravenous urography play a role? Ugeskr Laeger 1996:158:274-7.

11 Smellie JM, Rigden SP, Prescod NP. Urinary tract infections: a comparison of four methods of investigations. Arch Dis Child 1995;72:247-50. 